International Journal of Research in Advent Technology, Vol.7, No.3, March 2019

E-ISSN: 2321-9637

Available online at www.ijrat.org

\title{
Effect Of Transverse Load On Strain In Functionally Graded Material Plate For Varying Aspect Ratio
}

\author{
Manish Bhandari ${ }^{1}$ \\ Mechanical Engg. Department, MBM Engg. College, JNV University, Jodhpur \\ Email: manishbha78@gmail.com.Mo: 9413509699 \\ ${ }^{1}$ Corresponding author
}

\begin{abstract}
The concept of Functionally graded material (FGM) hinges on materials science and mechanics due to the integration of the material and structural considerations into the final design of structural components. Since the FGMs are used in place of homogeneous materials, it is vital to visualize the comparison of the characteristics of FGMs and homogeneous materials. These studies are concerned with stress, deformation and stability problems of FGM plates accounting for various effects, such as geometric and physical non-linearity and transverse shear deformability. A number of approaches have been employed to study the static bending problems of FGM plates. The present paper deals with the study of FGM plate subject to mechanical transverse loading with varying aspect ratio. The strain and shear strain values have been computed for P-FGM and S-FGM. Further a comparison of stain and shear strain for P-FGM, S-FGM and E-FGM have been presented.
\end{abstract}

Index Terms: FGM; Mechanical; strain; shear strain.

\section{INTRODUCTION}

The concept of Functionally graded material (FGM) hinges on materials science and mechanics due to the integration of the material and structural considerations into the final design of structural components. Since the FGMs are used in place of homogeneous materials, it is vital to visualize the comparison of the characteristics of FGMs and homogeneous materials. These studies are concerned with stress, deformation and stability problems of FGM plates accounting for various effects, such as geometric and physical non-linearity and transverse shear deformability. A number of approaches have been employed to study the static bending problems of FGM plates. Li et. al. ${ }^{1}$ chose ethylene carbon monoxide copolymer (ECO) to make the specimen because of its rapid degradation under UV light. They produced specimens with continuously varying mechanical properties. A hybrid numerical-experimental method was used to evaluate parameters in functionally grade materials. Ferreira et. al. ${ }^{2}$ utilized collocation multi-quadratic radial basis functions to analyze static deformation of a functionally graded plate modeled by third order shear deformation theory. It was concluded that the collocation method took quite less time to solve the problem as compared to MLPG. Ki-Hoon ${ }^{3}$ optimized both geometry and material distribution over the design domain. Having modeled and meshed the FEA based software (ANSYS) was used to perform linear elastic analysis to estimate the stress levels. Tahani et. al. ${ }^{4}$ developed analytical method to analyze displacements and stresses in a functionally graded composite beam subjected to transverse load. Equilibrium equations were obtained by minimum total potential energy approach. Shyang and Yen ${ }^{5}$ studied the effect of loading conditions, the change of Poisson's ratio and the aspect ratio on the mechanical behavior of an FGM plate. The closed form solutions of the deflection, strain and stress were also derived. Hui and Qing-Hua $^{6}$ developed the method of fundamental solutions coupling with radial basis functions (MFS-RBF) on the basis of analog equation theory, a mesh-less algorithm to simulate the static thermal stress distribution in two-dimensional (2D) functionally graded materials (FGMs). Mahdavian ${ }^{7}$ obtained the equilibrium and stability equations and found that the critical buckling coefficients for FGM plates are considerably higher than isotropic plates. Suresh et. al. ${ }^{\mathbf{8}}$ studied the effect of shear deformation and non-linearity response of functionally graded material plate and concluded that the effect of non-linearity in functionally graded composite plates is to decrease the central deflections with increase of side to thickness ratio. Bhandari ${ }^{9}$ developed finite element formulation and solve the mechanics problem of FM plate. Alieldin et. al. ${ }^{10}$ proposed three approaches to determine the property details of an FGM plate equivalent to the original laminated composite plate. Nguyen et. al. ${ }^{\mathbf{1 1}}$ presented an improved finite element approach in which a node-based strain smoothing is merged into shear-locking-free triangular plate elements. Yasser and Naotake ${ }^{12}$ used the homogenization method (HM) based on the finite element method (FEM) as it has advantages, such as it is appropriate for estimating the effective properties of fiber reinforced composites. Bhandari ${ }^{\mathbf{1 3}}$ considered FGM plate as structural member and applied various loading conditions to prsent the behaviour of the plae. Sharma ${ }^{\mathbf{1 4}}$ used power law, and MoriTanaka homogenization scheme to evaluate the properties at a particular thickness coordinate of FGM plate by controlling the volume fraction of the constituent materials (i.e., ceramic and metal). Moita et. Al. ${ }^{15}$ used finite element model based 
on a triangular flat plate/shell element, with three nodes and eight degrees of freedom per node, associated with a higher order shear deformation theory.

The present paper deals with the study of FGM plate subject to mechanical transverse loading with varying aspect ratio. The strain and shear strain values have been computed for P-FGM and S-FGM. Further a comparison of stain and shear strain for P-FGM, S-FGM and E-FGM have been presented.

\section{METHODOLOGY}

\subsection{Material:}

FGM is made up of ceramic and metal. The metal for the FGM is taken as Aluminum and the ceramic is Zirconia (Al$\mathrm{ZrO}_{2}$ ). The physical properties e.g. modulus of elasticity, Poisson's ratio, density etc. of Aluminum and Zirconia are used as input to calculate the variation in the volume fraction.

\subsection{Gradation:}

The material gradation is governed by Power law, Sigmoid law and Exponential law. The volume fraction is calculated using these laws and accordingly material properties are evaluated along the thickness of the plate. The analysis is performed various values of the volume fraction exponent (n) in P-FGM and S-FGM. The values of volume fraction exponent $(\mathrm{n})$ are: $\mathrm{n}=0$ (ceramic), $0.1,0.2,0.5,1,2,5,10$, $100, n=$ infinity (metal).

\subsection{Load and dimensions:}

A simply supported FGM plate with varying aspect ratio is considered here. The mechanical analysis is performed by applying uniformly distribute load (udl) and central point load $\left(10^{6} \mathrm{~N}\right)$ for various aspect ratio of plate.

\subsection{Numerical method:}

Finite element method is used to analyse and calculate various non-dimensional parameters e.g. strain $\left(\mathrm{e}_{\mathrm{x}}\right)$ and shear strain $\left(\mathrm{e}_{\mathrm{xy}}\right)$. The ANSYS software has been used to model and calculate the parameters of the plate.

\section{RESULTS}

\subsection{Uniformly distributed load}

In this section, the results of the analysis performed on FGM plate with varying aspect ratio subject to constant uniformly distributed load are discussed. The FGM plate is considered to be simply supported. The effect of various volume fractions and various laws i.e. P-FGM and S-FGM are studied. The results are presented in terms of nondimensional parameters i.e. strain $\left(e_{x}\right)$ and shear strain $\left(e_{x y}\right)$.

\subsubsection{Strain $\left(e_{x}\right)$}

The variation in strain $\left(e_{\mathrm{x}}\right)$ with change in in aspect ratio $(\mathrm{a} / \mathrm{b})$ for simply supported plate under uniformly distributed load for P-FGM and S-FGM are shown in Fig. 1 and Fig. 2 respectively. The comparison of results for various values of volume fraction exponent (n) for P-FGM and S-FGM have been presented.

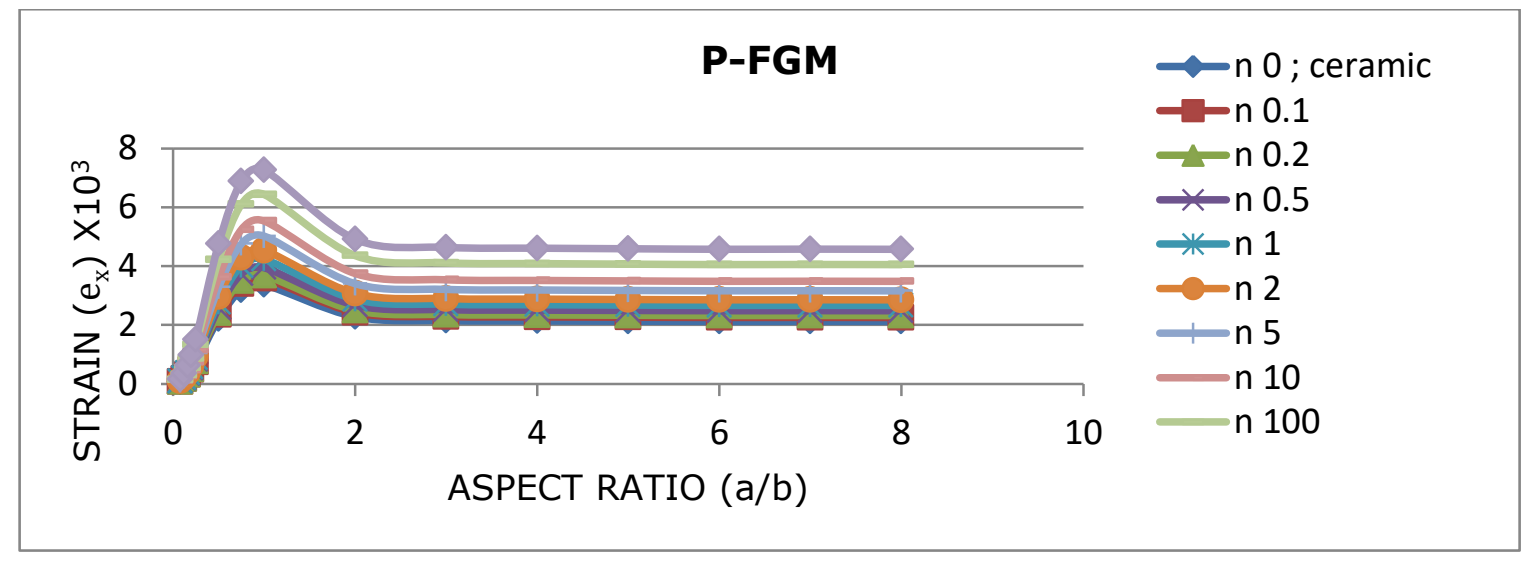

Fig. 1: Effect of aspect ratio $(\mathrm{a} / \mathrm{b})$ on strain $\left(\mathrm{e}_{\mathrm{x}}\right)$ for simply supported plate under udl for P-FGM 


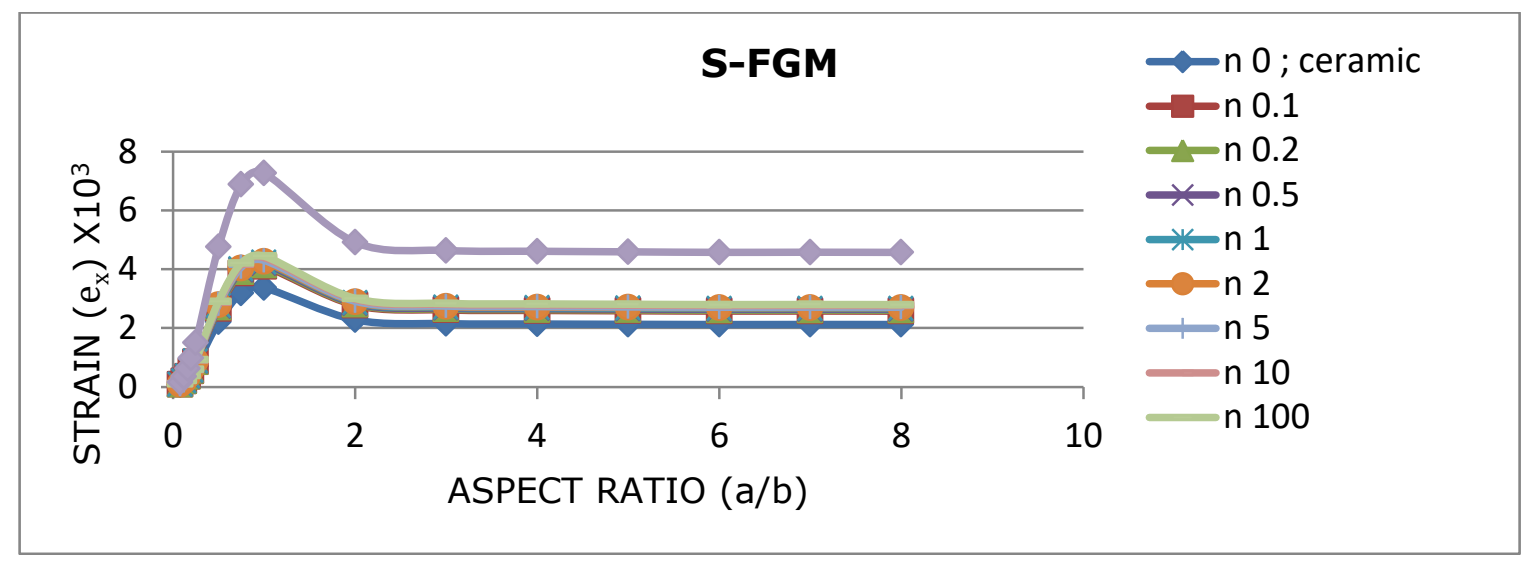

Fig. 2: Effect of aspect ratio $(\mathrm{a} / \mathrm{b})$ on strain $\left(\mathrm{e}_{\mathrm{x}}\right)$ for simply supported plate under udl for S-FGM

It can be observed from Fig. 1 and Fig. 2 that

(a) The strain $\left(e_{x}\right)$ increases as the aspect ratio is increased, it reaches maximum value $(0.0073)$ at aspect ratio 1 , then it reduces as the aspect ratio increases beyond 1 and it becomes constant as aspect ratio is increased beyond 3 . This suggests that maximum strain is obtained in case of square plate.

(b) The strain $\left(e_{\mathrm{x}}\right)$ is maximum in the case of pure metal ( $\mathrm{n}$ $=\infty)$ and minimum in the case of pure ceramic $(\mathrm{n}=0)$.

(c) The strain $\left(e_{x}\right)$ for S-FGM remains closer for various values of ' $n$ ' as compared to that of the P-FGM.

\subsubsection{Shear Strain $\left(e_{x y}\right)$}

The variation of shear strain $\left(e_{x y}\right)$ with aspect ratio $(a / b)$ for simply supported plate under uniformly distributed load for P-FGM and S-FGM are shown in Fig. 3 and Fig. 4 respectively. The comparison of results for various values of volume fraction exponent ' $\mathrm{n}$ ' for P-FGM and S-FGM have been presented.

It can be observed from Fig. 3 and Fig. 4 that

(a) The shear strain $\left(e_{x y}\right)$ increases as the aspect ratio is increased, it reaches maximum value $(0.026)$ at aspect ratio 2 , it becomes constant as the aspect ratio is increased beyond the value 4 .

(b) The shear strain $\left(e_{x y}\right)$ is maximum in the case of pure metal $(n=\infty)$ and minimum in the case of pure ceramic $(n$ $=0)$.

(c) The shear strain $\left(e_{x y}\right)$ for S-FGM remains closer for various values of ' $n$ ' compared to that of the P-FGM which is due to more uniform material gradation obtained in $\mathrm{S}$ FGM.

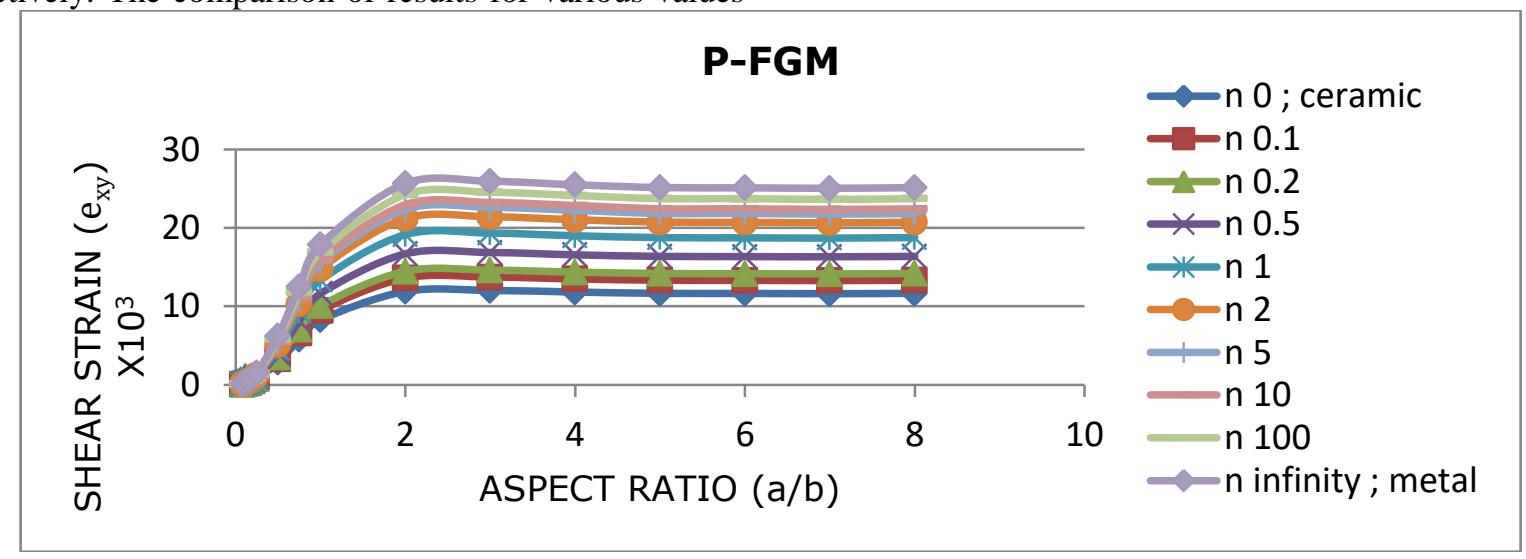

Fig. 3: Effect of aspect ratio $(a / b)$ on shear strain $\left(e_{x y}\right)$ for simply supported plate under udl for P-FGM 
Available online at www.ijrat.org

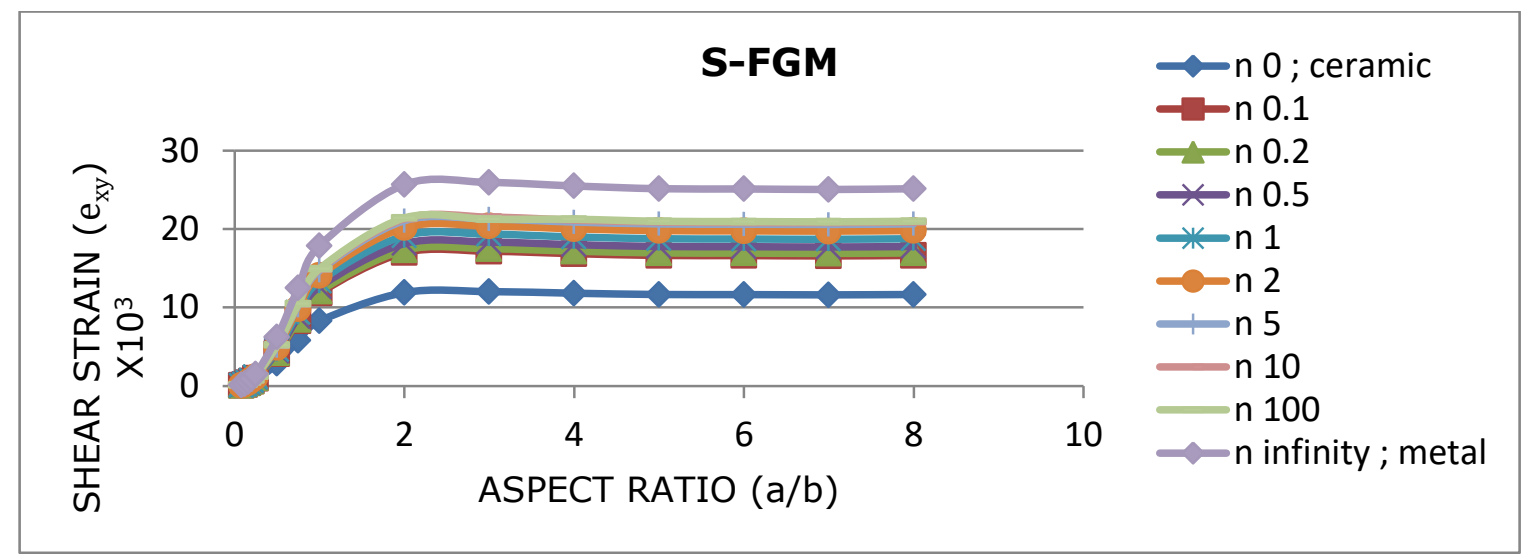

Fig. 4: Effect of aspect ratio $(a / b)$ on shear strain $\left(e_{x y}\right)$ for simply supported plate under udl for S-FGM

\subsection{Comparison of P-FGM, S-FGM, E-FGM, ceramic and metal (udl)}

It is also interesting to see the comparison of various parameters like strain and shear strain for ceramic, metal and FGM's following Power law, Sigmoid law and Exponential law. In this study, for FGM plate, the comparison has been made for constant value of volume fraction exponent ' $n$ '. The Fig. 5 and Fig. 6 show the graphs between aspect ratio and respective non-dimensional parameters for pure ceramic $(\mathrm{n}=0)$, pure metal $(\mathrm{n}=\infty)$, P-FGM $(\mathrm{n}=2)$, P-FGM $(\mathrm{n}=0.5)$, S-FGM $(n=2), S-F G M(n=0.5)$ and E-FGM.

\subsubsection{Strain $\left(e_{x}\right)$}

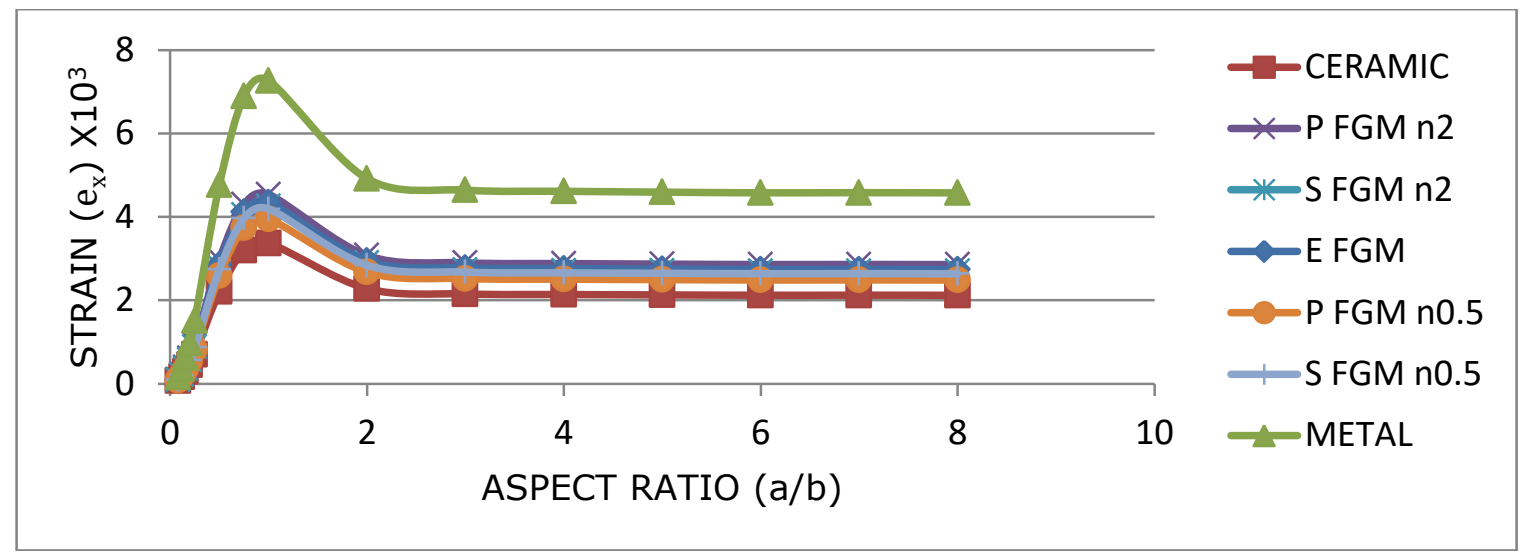

Fig. 5: Effect of aspect ratio $(\mathrm{a} / \mathrm{b})$ on strain $\left(\mathrm{e}_{\mathrm{x}}\right)$ for simply supported plate under udl for various FGM's, ceramic and metal 
International Journal of Research in Advent Technology, Vol.7, No.3, March 2019

E-ISSN: 2321-9637

Available online at www.ijrat.org

3.2.2 Shear Strain $\left(\mathrm{e}_{\mathrm{xy}}\right)$

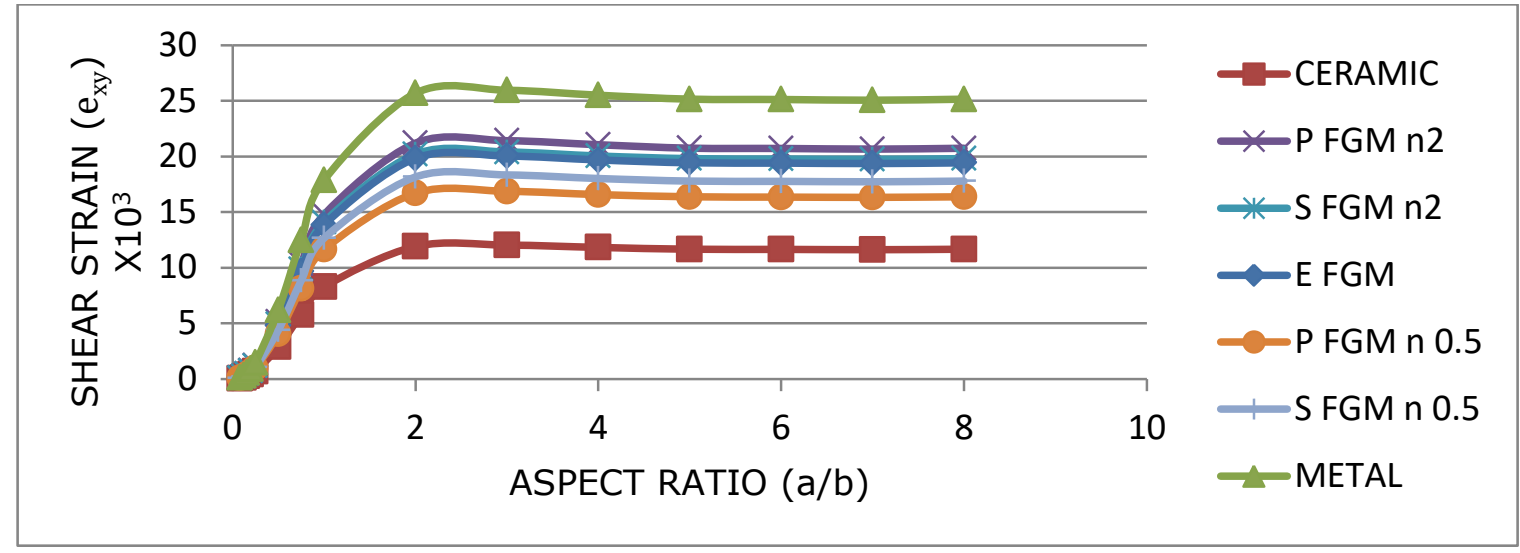

Fig. 6: Effect of aspect ratio $(a / b)$ on shear strain $\left(e_{x y}\right)$ for simply supported plate under udl for various FGM's, ceramic and metal

Comparison of parameters for pure ceramic $(n=0)$, pure metal $(n=\infty)$, P-FGM $(n=2)$, P-FGM $(n=0.5)$, S-FGM $(n=2), S-F G M(n=0.5)$ and E-FGM for square plate (aspect ratio $\mathrm{a} / \mathrm{b}=1)$ is given below:

a. The non-dimensional strain and shear strain for the FGM's are in between that of ceramic and metal.

b. The strain $\left(e_{x}\right)$ in case of P-FGM-n2 $\left(e_{x}=0.0045\right)$ is found to be greater than that of S-FGM-n2 $\left(e_{x}=0.0043\right)$. At the same time the strain $\left(\mathrm{e}_{\mathrm{x}}\right)$ in case of P-FGM-n0.5 $\left(\mathrm{e}_{\mathrm{x}}=\right.$ $0.0039)$ is found to be less than that of S-FGM-n0.5 $\left(e_{x}\right.$ $=0.0042$ ).

c. The shear strain $\left(e_{x y}\right)$ in case of P-FGM-n2 $\left(e_{x y}=\right.$ 0.0148 ) is found to be greater than that of S-FGM-

d. $n 2 \quad\left(e_{x y}=0.0141\right)$. At the same time the nondimensional shear strain in case of P-FGM-n0.5 $\left(\mathrm{e}_{\mathrm{xy}}=\right.$ $0.012)$ is found to be less than that of S-FGM-n0.5 $\left(\mathrm{e}_{\mathrm{xy}}\right.$ $=0.0127$ ).

e. The strain $\left(e_{x}\right)$ for E-FGM $\left(e_{x}=0.0043\right)$ lies in between that of P-FGM-n2 $\left(e_{x}=0.0045\right)$ and P-FGM-n0.5 $\left(\mathrm{e}_{\mathrm{x}}=0.0039\right)$.

f. The shear strain $\left(e_{x y}\right)$ for E-FGM $\left(e_{x y}=0.014\right)$ lies in between that of P-FGM-n2 $\left(\mathrm{e}_{\mathrm{xy}}=0.0148\right)$ and P-FGM-n0.5 $\left(\mathrm{e}_{\mathrm{xy}}=0.0125\right)$.

It is evident from the above comparison that P-FGM $(\mathrm{n}=0.5)$ plate has the smallest strain among all kinds of FGM plate.

\subsection{Mechanical point load}

It is found from the literature that most of the researchers have analyzed a FGM plate with uniformly distributed load, however behaviour of FGM plate with point load is relatively sparse. In the present work author has made an attempt to analyze the FGM plate with point load equivalent to the magnitude $\left(10 \times 10^{5} \mathrm{~N} / \mathrm{m}^{2}\right)$ located at the geometric center of the plate. The results of the analysis performed on FGM plate subjected to point load with varying aspect ratio are presented. The results are reported in terms of non- dimensional parameters i.e. strain $\left(\mathrm{e}_{\mathrm{x}}\right)$ and shear strain $\left(\mathrm{e}_{\mathrm{xy}}\right)$.

\subsubsection{Strain $\left(e_{x}\right)$}

The variation in strain $\left(e_{x}\right)$ with change in aspect ratio $(a / b)$ for simply supported plate under point load for P-FGM and S-FGM are shown in Fig. 7 and Fig. 8 respectively. The comparison of results for various values of volume fraction exponent ' $n$ ' for P-FGM and S-FGM have been presented. Comparison of results for P-FGM and S-FGM from Fig. 7 and Fig. 8 reveals the following informations:

(a) The slope of strain $\left(e_{x}\right)$ increases with increasing aspect ratio upto 1 and beyond the value 1 the slope of the strain reduces with increasing the aspect ratio.

(b) The strain $\left(e_{x}\right)$ is maximum in the case of pure metal ( $n$ $=\infty)$ and minimum in the case of pure ceramic $(n=0)$, this is due to the elastic properties of the material.

(c) The strain $\left(\mathrm{e}_{\mathrm{x}}\right)$ for P-FGM is fairly distributed for different values of volume fraction exponent ' $n$ ' whereas in case of S-FGM the volume fraction exponent ' $n$ ' has little influence on it.

(d) The value of strain $\left(e_{x}\right)$ for square plate is approximately 0.06 metal plate. The strain $\left(\mathrm{e}_{\mathrm{x}}\right)$ is much higher (0.06) when point load is applied as compared to that in the case of application of udl (0.0072) for a square plate. 


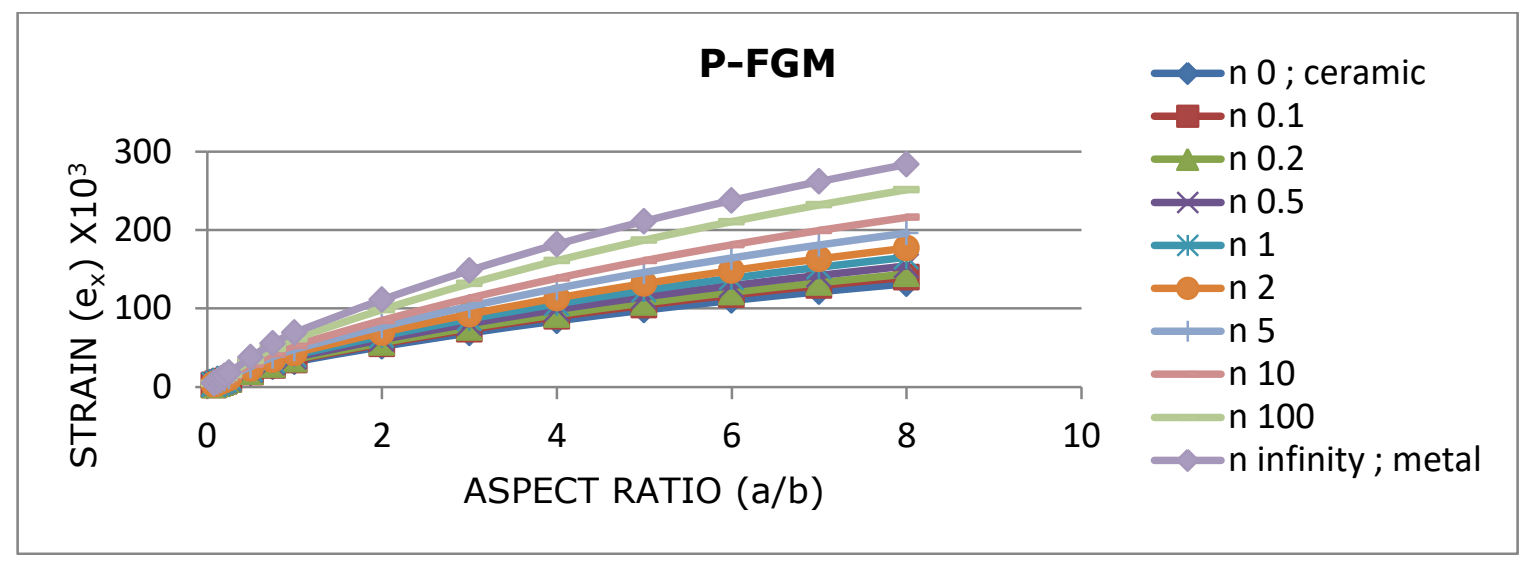

Fig. 7: Effect of aspect ratio $(a / b)$ on strain $\left(e_{x}\right)$ for simply supported plate under point load for P-FGM

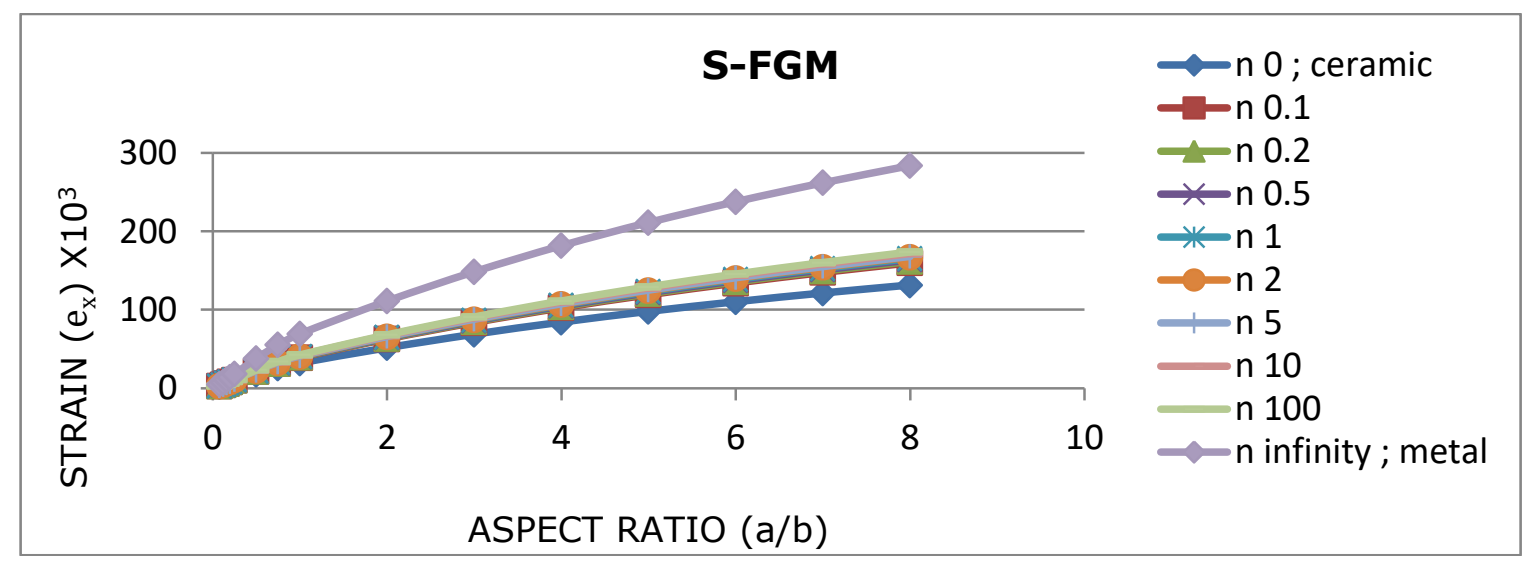

Fig. 8: Effect of aspect ratio $(\mathrm{a} / \mathrm{b})$ on strain $\left(\mathrm{e}_{\mathrm{x}}\right)$ for simply supported plate under point load for S-FGM

\subsubsection{Shear Strain $\left(e_{x y}\right)$}

Fig. 9 and Fig. 10 show the variation of shear strain $\left(e_{x y}\right)$ with aspect ratio $(\mathrm{a} / \mathrm{b})$ for simply supported plate under point load for P-FGM and S- FGM respectively. The comparison of results for various values of volume fraction exponent ' $n$ ' for P-FGM and S-FGM have been presented. It can be observed from Fig. 9 and Fig. 10 that

(a) The shear strain $\left(e_{x y}\right)$ increases rapidly as the aspect ratio increases upto 1 and then the slope of the shear strain reduces as the aspect ratio is increased upto value 2 . It suggests that the rate of change of shear strain is more when the plate dimensions are nearer to a square plate. Further when aspect ratio is increased beyond 2, it is found that slope of shear strain is almost constant for a given value of volume fraction exponent $(b)$ The shear strain $\left(e_{x y}\right)$ is found to be maximum in the case of pure metal $(n=\infty)$ and minimum in the case of pure ceramic $(n=0)$.

(c) The shear strain $\left(e_{x y}\right)$ for S-FGM remains in closer band for various values of volume fraction exponent ' $n$ ' as compared to that of the P-FGM which is due to more uniform material gradation obtained in S-FGM.

(d) The maximum value of shear strain $\left(e_{x y}\right)$ is approximately 0.036 in both P-FGM and S-FGM. The shear strain $\left(\mathrm{e}_{\mathrm{xy}}\right)$ is higher $(0.036)$ when point load is applied as compared to that in the case of application of udl (0.026) for a square plate. 
Available online at www.ijrat.org

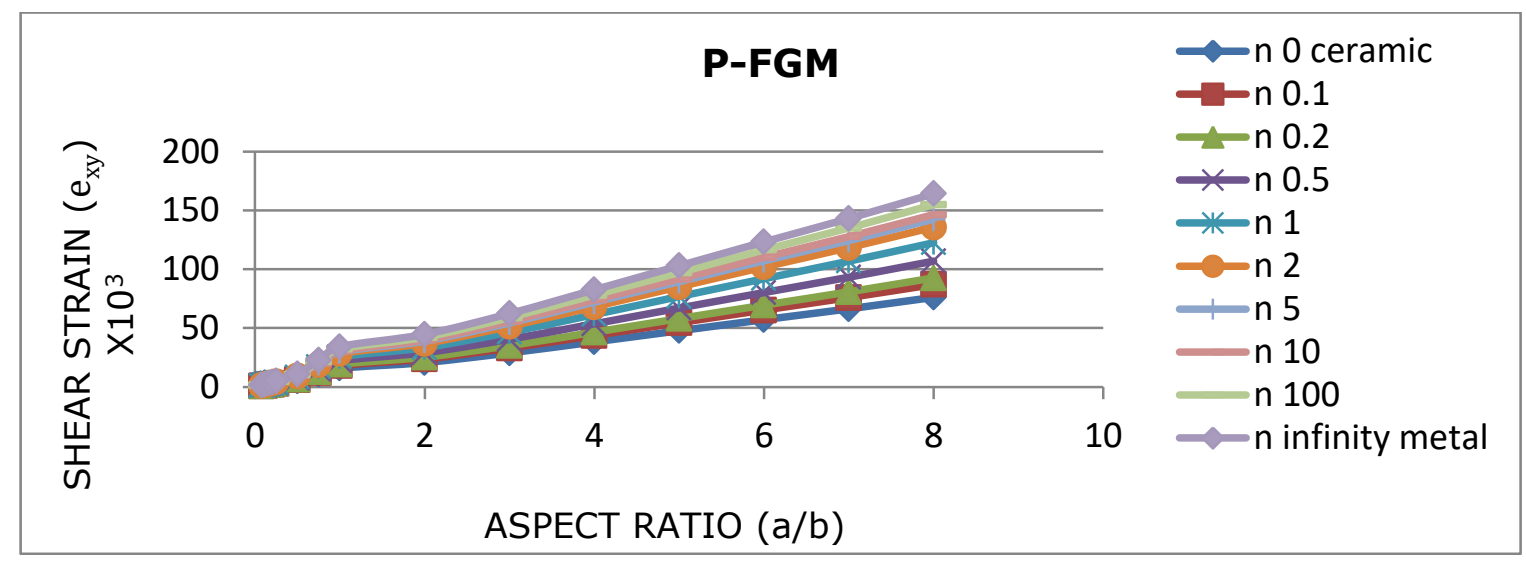

Fig. 9: Effect of aspect ratio $(\mathrm{a} / \mathrm{b})$ on shear strain $\left(\mathrm{e}_{\mathrm{xy}}\right)$ for simply supported plate under point load for P-FGM

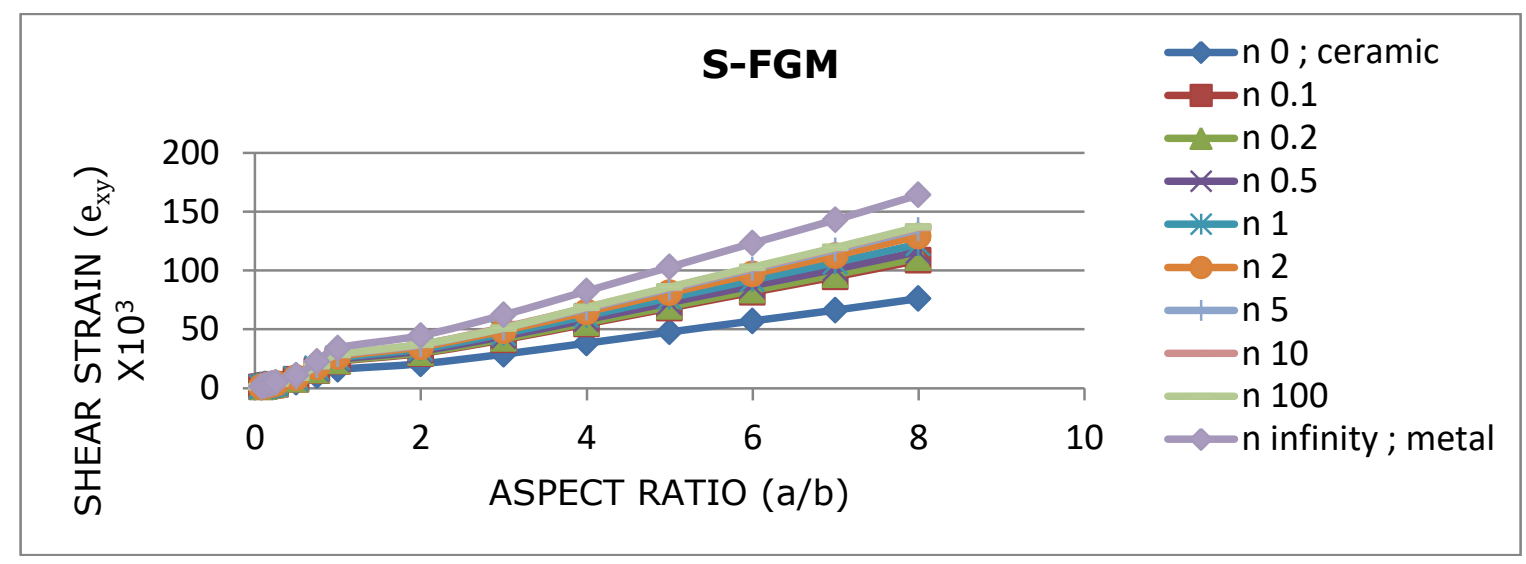

Fig. 10: Effect of aspect ratio $(a / b)$ on shear strain $\left(e_{x y}\right)$ for simply supported plate under point load for S-FGM

\subsection{Comparison of P-FGM, S-FGM, E-FGM, ceramic and metal (point load)}

It is also interesting to see the comparison of various parameters like strain and shear strain for ceramic, metal and FGM's following Power law, Sigmoid law and Exponential law. In this study, for FGM plate, the comparison has been made for constant value of volume fraction exponent ' $n$ '.

The Fig. 11 and Fig. 12 show the graphs between aspect ratio and respective non-dimensional parameters for pure ceramic $(n=0)$, pure metal $(n=\infty)$, P-FGM $(n=2)$, P-FGM $(n=0.5), S-F G M(n=2), S-F G M(n=0.5)$ and E-FGM. 
International Journal of Research in Advent Technology, Vol.7, No.3, March 2019

E-ISSN: 2321-9637

Available online at www.ijrat.org

3.4.1 Strain $\left(e_{x}\right)$

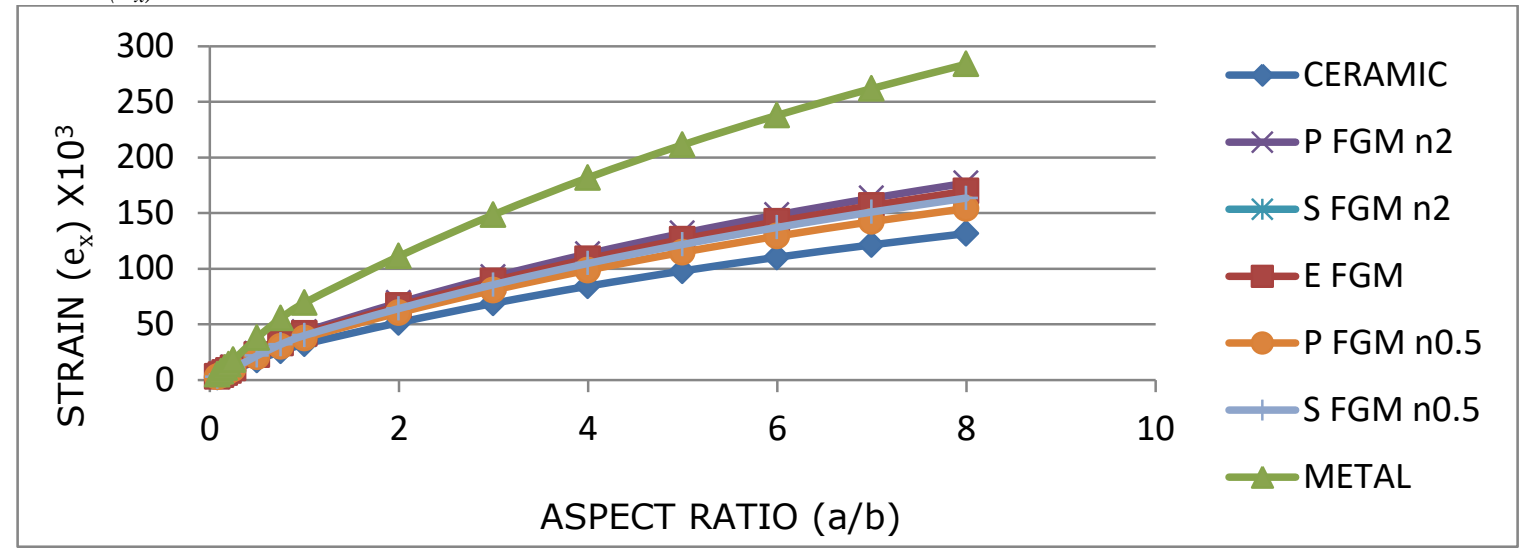

Fig. 11: Effect of aspect ratio $(\mathrm{a} / \mathrm{b})$ on strain $\left(\mathrm{e}_{\mathrm{x}}\right)$ for simply supported plate under point load for various FGM's, ceramic and metal

\subsubsection{Shear Strain $\left(e_{x y}\right)$}

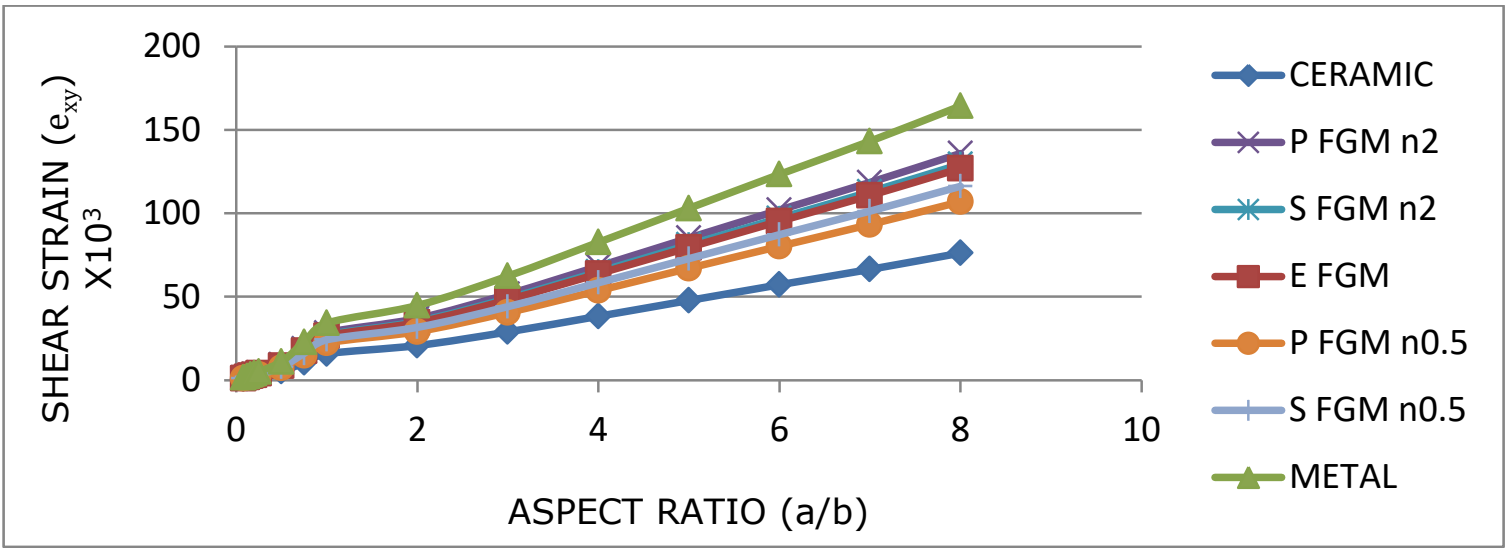

Fig. 12: Effect of aspect ratio $(\mathrm{a} / \mathrm{b})$ on shear strain $\left(\mathrm{e}_{\mathrm{xy}}\right)$ for simply supported plate under point load for various FGM's, ceramic and metal

Comparison of parameters for pure ceramic $(n=0)$, pure metal $(n=\infty)$, P-FGM $(n=2)$, P-FGM $(n=0.5)$, S-FGM $(n=2), S-F G M \quad(n=0.5)$ and E-FGM for square plate (aspect ratio $\mathrm{a} / \mathrm{b}=1$ ) is given below:

a. The characteristics of P-FGM and E-FGM are closer to each other as compared to that of S-FGM.

b. The strain and shear strain for the FGM's are in between that of ceramic and metal.

c. The strain $\left(e_{x}\right)$ in case of P-FGM-n2 $\left(e_{x}=0.043\right)$ is found to be greater than that of S-FGM-n2 $\left(e_{x}=0.041\right)$. At the same time the strain $\left(\mathrm{e}_{\mathrm{x}}\right)$ in case of P-FGM-n0.5 $\left(\mathrm{e}_{\mathrm{x}}=\right.$
$0.037)$ is found to be less than that of S-FGM-n0.5 $\left(\mathrm{e}_{\mathrm{x}}\right.$ $=0.04)$.

d. The shear strain $\left(e_{x y}\right)$ in case of P-FGM-n2 $\left(e_{x y}=\right.$ $0.028)$ is found to be greater than that of S-FGM-n2 $\left(\mathrm{e}_{\mathrm{xy}}=0.027\right)$.

e. The strain $\left(e_{x}\right)$ for E-FGM $\left(e_{x}=0.041\right)$ lies in between that of P-FGM-n2 $\left(\mathrm{e}_{\mathrm{x}}=0.043\right)$ and P-FGM-n0.5 $\left(\mathrm{e}_{\mathrm{x}}=\right.$ 0.037).

f. The shear strain $\left(e_{x y}\right)$ for E-FGM $\left(e_{x y}=0.026\right)$ lies in between that of P-FGM-n2 $\left(\mathrm{e}_{\mathrm{xy}}=0.028\right)$ and P-FGM$\mathrm{n} 0.5\left(\mathrm{e}_{\mathrm{xy}}=0.022\right)$. 
International Journal of Research in Advent Technology, Vol.7, No.3, March 2019 E-ISSN: 2321-9637

Available online at www.ijrat.org

It is evident from the above comparison that P-FGM $(n=0.5)$ plate has the smallest strain among all kinds of FGM plate.

\section{CONCLUSION}

The behaviour of FGM plate under mechanical load environment was studied. The work includes parametric study performed by varying volume fraction distribution and types of load. The following conlcusions may be drawn:

(a) As the volume fraction exponent ' $n$ ' increases the non-dimensional deflection increases. This is due to the fact that the bending stiffness is the maximum for ceramic plate, while minimum for metallic plate, and degrades continuously as ' $\mathrm{n}$ ' increases. The nondimensional tensile stress increases as the aspect ratio is increased and it attains maximum value for square plate. The value of non- dimensional shear stress $\left(\overline{\sigma_{x y}}\right)$ is maximum for a plate of aspect ratio 2 . The value of non-dimensional deflection, tensile stress, shear stress, strain and shear strain for the FGM's are in between that of ceramic and metal.

(b) The values of non-dimensional characteristics are highly increased when the FGM plate is subjected to point load though the total load is kept same. This is due to the fact that in the case of UDL the load is uniformly distributed and whereas the point load is concentrated at a point. The strain $\left(\mathrm{e}_{\mathrm{x}}\right)$ increases with increasing value of volume fraction exponent ' $n$ '.

\section{REFERENCES}

[1] Li, H; Lambros, J; Santare, M.H. (2000): Experimental Investigation of quasi-static fracture of functionally graded materials. Int $\mathbf{J}$ of Solids and Structures, 37, pp. 3715-3702.

[2] Ferreira, A.J.M.; Batra, R.C.; Roque, C.M.C.; Qian, L.F.; Martins PALS. (2005): Static Analysis of Functionally Graded Plates Using Third Order Shear Deformation Theory and A Meshless Method. Compo. Struct.,69, pp. 449-457.

[3] Ki-Hoon, S. (2006): Fea Based Design of Heterogeneous Objects. Int Design Engg. Technical Conferences \& Computers and Information in Engg. Conference, Philadelphia, Pennsylvania, Usa, September 2006, pp. 10-13.

[4] Tahani, M; Torabizadeh, M.A.; Fereidoon, A. (2006): Non-Linear Response of Functionally Graded Beams under Transverse Loads. $14^{\text {th }}$ Annual (Int) Technical Engg. Conference Isfahan University of Technology Isfahan, Iran; 2006.

[5] Shyang-Ho, C.; Yen-Ling, C. (2006): Mechanical Behavior of Functionally Graded Material
Plates under Transverse Load-Part I: Analysis. Int J of Solids and Structures. 43, pp. 3657-3674.

[6] Hui, W; Qing-Hua, Q. (2008): Meshless Approach for Thermo-Mechanical Analysis of Functionally Graded Materials. Engg. Analysis with Boundary Elements. 32, pp. 704-712.

[7] Mahdavian, M. (2009): Buckling Analysis of Simply-Supported Functionally Graded Rectangular Plates under Non-Uniform In-Plane Compressive Loading. J of Solid Mechanics. 1, pp. 213-225.

[8] Suresh, K.J.; Sidda, R.B.; Eswara, R.C.; Vijaya, K.R.K. (2011): Geometrically Non Linear Analysis of Functionally Graded Material Plates Using Higher Order Theory. Int $\mathbf{J}$ of Engg. Science and Technology. 3, pp. 279-288.

[9] Bhandari, M.; Purohit, K. (2015): Response of Functionally Graded Material Plate under Thermomechanical Load Subjected to Various Boundary Conditions. International Journal of Metals. 2015.

http://dx.doi.org/10.1155/2015/416824.

[10] Alieldin, S.S.; Alshorbagy, A.E.; Shaat, A. (2011): First-Order Shear Deformation Finite Element Model for Elastostatic Analysis of Laminated Composite Plates and the Equivalent Functionally Graded Plates. Ain Shams Engg. J. 2, pp. 53-62.

[11] Nguyen-Xuan, H; Locv, T.; Chienh, T.; Nguyen-Thoi, T. (2012): Analysis of Functionally Graded Plates by an Efficient Finite Element Method with Node-Based Strain Smoothing. Thin-Walled Structures. 54, pp. 1-18.

[12] Yasser, M.S.; Naotake, N. (2008): Numerical Evaluation of The Thermo mechanical Effective Properties of a Functionally Graded Material Using the Homogenization Method. Int $\mathbf{J}$ of Solids and Structures. 45, pp. 3494-3506.

[13] Bhandari, M.; Purohit, K. (2014): Static Response of Functionally Graded Material Plate under Transverse Load for Varying Aspect Ratio. International Journal of Metals. 2014. http://dx.doi.org/10.1155/2014/980563.

[14] Sharma, K.; Kumar, D. (2017): Elastoplastic Stability and Failure Analysis of FGM Plate with Temperature Dependent Material Properties under Thermomechanical Loading. Latin American Journal of Solids and Structures. 14, pp.1361-1386.

[15] Moita, J.; Araújo, A; Correia, V.; Soares, C.; Herskovits, J. (2018): Buckling and nonlinear response of functionally graded plates under thermo-mechanical loading. Composite Structures. 202, pp.719-730. 